Research Article

\title{
Study on Probabilistic Safety Goals for Multimodule High-Temperature Gas-Cooled Reactor Based on Chinese Societal Risks
}

\author{
Jinghan Zhang $\mathbb{D}$, Jun Zhao $\mathbb{D}$, and Jiejuan Tong $\mathbb{1}$ \\ Tsinghua University, Institute of Nuclear and New Energy Technology, Beijing 100084, China \\ Correspondence should be addressed to Jiejuan Tong; tongjj@mail.tsinghua.edu.cn
}

Received 18 February 2021; Accepted 27 May 2021; Published 7 June 2021

Academic Editor: Alejandro Clausse

Copyright (C) 2021 Jinghan Zhang et al. This is an open access article distributed under the Creative Commons Attribution License, which permits unrestricted use, distribution, and reproduction in any medium, provided the original work is properly cited.

\begin{abstract}
Nuclear safety goal is the basic standard for limiting the operational risks of nuclear power plants. The statistics of societal risks are the basis for nuclear safety goals. Core damage frequency (CDF) and large early release frequency (LERF) are typical probabilistic safety goals that are used in the regulation of water-cooled reactors currently. In fact, Chinese current probabilistic safety goals refer to the Nuclear Regulatory Commission (NRC) and the International Atomic Energy Agency (IAEA), and they are not based on Chinese societal risks. And the CDF and LERF proposed for water reactor are not suitable for high-temperature gas-cooled reactors (HTGR), because the design of HTGR is very different from that of water reactor. And current nuclear safety goals are established for single reactor rather than unit or site. Therefore, in this paper, the development of the safety goal of NRC was investigated firstly; then, the societal risks in China were investigated in order to establish the correlation between the probabilistic safety goal of multimodule HTGR and Chinese societal risks. In the end, some other matters about multireactor site were discussed in detail.
\end{abstract}

\section{Introduction}

Nuclear energy is a special kind of energy source with many advantages and it is conducive to solving the energy crisis [1]. However, a large amount of radioactive materials will be produced when using nuclear energy, and they seriously threaten the surroundings. So far, there have been three major nuclear accidents in the world: the Three Mile Island nuclear accident in the United States, the Chernobyl nuclear accident in the former Soviet Union, and the Fukushima nuclear accident in Japan. Each nuclear accident seriously damaged human health and the surrounding environment [2]. Due to the adverse effects of a nuclear accident, we need to ensure the safe design, safe construction, and safe operation of nuclear power plants to reassure the public's concerns and doubts.

Nuclear safety goals are set to control the severity of the adverse effects on the public and environment when nuclear power plants are in operation or accidents occur. On the one hand, the safety goals can be used to guide the design, operation, and management of nuclear power plants, to establish a set of effective protection measures in nuclear power plants to protect personnel, society, and the environment from radioactive hazards. On the other hand, reasonable safety goals can promote public understanding of the safety of nuclear energy and have a positive impact on the development of nuclear energy. In order to promote the realization of nuclear safety goals and to make the safety goals more applicable in the actual design and management of nuclear power plants, the subsidiary numerical safety goals are always defined and used as surrogate safety goals for qualitative and quantitative safety goals. Core damage frequency $(\mathrm{CDF})$ and large early release frequency (LERF) are the typical probabilistic safety goals that are used to evaluate the safety of water-cooled reactors [3].

The modular pebble-bed high-temperature gas-cooled reactor (HTR-PM) is in the construction in China as a demonstration project. It includes one turbine and two 
reactors, and two reactors are used to drive one turbine [4]. The typical CDF and LERF which has been developed based on the characteristics of water-cooled reactors are not applicable to HTR-PM due to the unique design concept of high-temperature reactor (HTR). The most important difference is that core damage will not happen in the HTR. Therefore, the probabilistic safety goal of HTR-PM has been reestablished by China National Nuclear Safety Administration (NNSA); that is, "the cumulative frequency of all beyond design basis accident sequences that lead to off-site (including plant boundary) personal effective dose exceeding $50 \mathrm{mSv}$ shall be less than $10^{-6} /(r \cdot y)$." It should be noted that this safety goal is dedicated to HTR-PM project and it is focused on single reactor rather than unit (two reactors and one turbine). In order to promote the development of multimodule HTGR, the probabilistic safety goal based on the "unit" or "plant" must be studied.

According to the method of nuclear safety goal formulation, the societal risks statistics are the basis for nuclear safety goals. At present, the probabilistic safety goals (CDF and LERF) of Chinese nuclear power plants refer to the American nuclear safety goals, which are based on the societal risks of the United States rather than the societal risks of China. Therefore, it is necessary to investigate Chinese societal risks based on the mortality rate of statistical data to provide a basis for the probabilistic safety goals of multimodule HTGR.

This paper aims to study the probabilistic safety goals of multimodule HTGR to support the probabilistic safety assessment of high-temperature gas-cooled reactors. In Section 2, the existing nuclear safety goals in the International Atomic Energy Agency (IAEA), the United States Nuclear Regulatory Commission (NRC), and China have been investigated to provide technical references for verifying the value of the probabilistic safety goals of HTGR. And the formulation and evolution of United States National Nuclear Regulatory Commission (USNRC) has been studied in order to guide the development of probabilistic safety goals of multimodule HTGR. In Section 3, the societal risks in China and other countries have been investigated in detail to provide the basis for determining the value of the probabilistic safety goals of multimodule HTGR. In Section 4, the key aspects of development of probabilistic safety goals of multimodule HTGR have been studied, and the correlation between the probabilistic safety goals and Chinese societal risks has been established. The last section is the discussion and conclusion.

\section{Evolution of Safety Goals}

2.1. Overview of Existing Safety Goals. In a report published by the Organization for Economic Cooperation and Development/Nuclear Energy, probabilistic safety goals include the following four categories: core damage frequency (CDF); release frequencies, such as large release frequency (LRF) and large early release frequency (LERF); frequency of doses; and criteria on containment failure frequency (CFF) [3]. At present, many countries or organizations have formulated the probabilistic safety goals, including International Atomic
Energy Agency (IAEA) [5], US Nuclear Users Request Documentation (URD) [6], European Utility Requirement (EUR) [7], and European Pressurized Reactor (EPR) [8].

In this section, the probabilistic safety goals in IAEA, the US, and China were introduced, and the comparisons between the nuclear safety goals in China and the US were given.

(1) IAEA adopted the probabilistic safety goals of the US directly after the Chernobyl nuclear accident in 1986. During 1988-2001, IAEA issued INSAG-3, INSAG12, NS-G-1, and NS-G-1.2 for nuclear safety goals [9-12]. Current probabilistic safety goals of IAEA are as follows: for existing reactors, $\mathrm{CDF}<10^{-4} /($ reactor $\cdot$ year) (reactor $\cdot$ year, $r \cdot y)$, $\mathrm{LERF}<10^{-5} /(r \cdot y)$; for new reactors, $\mathrm{CDF}<10^{-5} /(r \cdot y)$, eliminate radioactive large release practically that require early off-site emergency response.

(2) The US is the first to quantify nuclear safety goals and combine deterministic theory and probabilistic theory in the study of technical safety goals. In 1986, Nuclear Regulatory Commission (NRC) issued the final nuclear power plant safety goals policy statement, which determined qualitative safety goals, quantitative safety goals, and subsidiary safety goals [13-15]. Current probabilistic safety goals of the US are as follows: for existing reactors, $\mathrm{CDF}<10^{-4} /(r \cdot y), \quad \mathrm{LERF}<10^{-5} /(r \cdot y)$.

(3) Chinese nuclear safety goals mainly refer to the nuclear safety goals of US and IAEA. Many laws and regulations have been issued in China, including HAF 102-1991, HAF102-2004, HAD102/17-2006, the 12th Five-Year Plan for Nuclear Safety, HAF1022016, and the 12th Five-Year Plan for Nuclear Safety [16-19]. Current probabilistic safety goals in China are as follows: for existing reactors, $\mathrm{CDF}<10^{-4} /(r \cdot y)$, LERF $<10^{-5} /(r \cdot y)$; for new reactors, $\mathrm{CDF}<10^{-5} /(r \cdot y), \operatorname{LERF}<10^{-6} /(r \cdot y)$.

The nuclear safety goal systems in China and the United States are shown in Figure 1. We compared the nuclear safety goals of China and the US from protection and prevention, qualitative safety goal, quantitative safety goal, and subsidiary safety goal. In fact, there is no specific quantitative safety goal in China.

2.2. Probabilistic Safety Goals of NRC. In this section, the evolution of safety goals of NRC was investigated, including the relationship between CDF and LERF with quantitative health objective (QHO).

2.2.1. Overview of Probabilistic Safety Goals of NRC. In 1979, the Three Mile Island nuclear accident occurred in the United States. After the accident, the proposal of establishing nuclear power reactor quantitative safety goals and perfecting safety principles was put forward. In 1980, the NRC issued a response to set nuclear safety goals. In 1981, the 


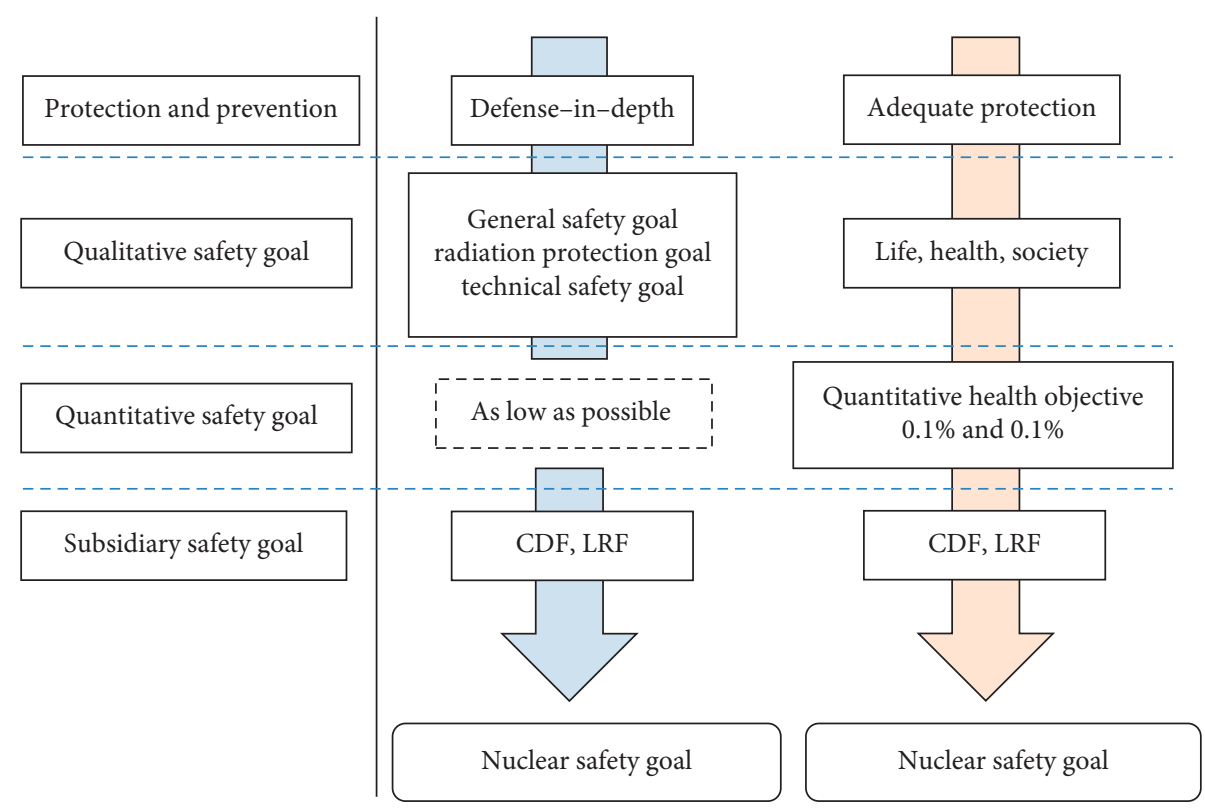

FIGURE 1: Nuclear safety goal systems in China and the United States.

NRC formulated a draft nuclear safety goals policy statement based on the results of expert seminars [13]. In 1983, the NRC issued a formal nuclear safety goals policy statement based on the results of discussions in various industries [14]. In 1986, the NRC issued a final nuclear safety goals policy statement and provided two qualitative safety goals and two quantitative safety goals [15].

Individual qualitative safety goal (IQSG) means prompt fatalities risks to an average individual in the vicinity of a nuclear power plant caused by reactor accidents. Societal qualitative safety goal (SQSG) means cancer fatalities to the population in the area of a nuclear power plant caused by nuclear power plant operation. Because the qualitative safety goal cannot be used to guide the design and operation of nuclear power plant (NPP), two quantitative safety goals have been proposed based on the two $0.1 \%$ rule, which include early quantitative health objective (EQHO) and latent quantitative health objective (LQHO).The EQHO and LQHO have been derived from the societal risk of America; that is, the risk to residents of NPP cannot exceed other existing societal risks obviously; this is the so-called "two $0.1 \%$ rule." The risk to the average individual in the vicinity of a nuclear power plant of prompt fatalities that might result from reactor accidents should not exceed $0.1 \%$ of the sum of prompt fatality risks resulting from other accidents to which members of the US population are generally exposed. The risk to the population in the area near a nuclear power plant of cancer fatalities that might result from nuclear power plant operation should not exceed $0.1 \%$ of the sum of cancer fatality risks resulting from all other causes [15].

CDF and LERF as subsidiary safety goals used to be surrogate safety goals of LQHO and EQHO, respectively, since the applicability of quantitative safety goals is still poor. The unit of CDF and LERF is per reactor year $(r \cdot y)$. The unit of the individual fatality risk is per year $(y)$. Based on the later assessments of the sites, surrounding environment, and demographic conditions of nuclear power plants in the US, $\mathrm{CDF}<10^{-4} /(r \cdot y)$ and $\mathrm{LERF}<10^{-5} /(r \cdot y)$ meet the $0.1 \%$ and $0.1 \%$ quantitative safety goals. The relationship among nuclear safety goals in the US is shown in Figure 2. The quantitative safety goals (IQSG and SQSG) mean that the operation of nuclear power plants will not cause obvious additional risks to the life and health of the public. Qualitative safety goals (EQHO and LQHO) are measured/ achieved through quantitative safety goals. Subsidiary safety goals (LERF and CDF) make quantitative safety goals more specific and easier to implement.

2.2.2. LERF and EQHO [20]. LERF $<10^{-5} /(r \cdot y)$ is a subsidiary goal of early quantitative health objectives (EQHO) for early prompt fatalities. The rationality of substituting LERF for EQHO is demonstrated as follows.

According to the data survey for nuclear safety goals, the individual risk of prompt fatality caused by all other accidents is $5 \times 10^{-4} / y$ in the US. These accidents include traffic accidents, production accidents, and other accidents. According to the $0.1 \%$ in the early quantitative health objective $(\mathrm{EQHO})$, the individual early risk $\left(\mathrm{IER}_{\mathrm{EQHO}}\right)$ caused by nuclear power plant accidents need to be less than $5 \times 10^{-7} /(r \cdot y)$. The vicinity of a nuclear power plant means an extension of 1 mile from the boundary of the nuclear power plant. Individual early risk (IER) is

$$
\operatorname{IER}=\sum_{1}^{M} \frac{\left(\mathrm{EF}_{m} * \mathrm{LERF}_{m}\right)}{\mathrm{TP}(1)}
$$

where $\mathrm{EF}_{m}$ is the number of early prompt fatalities within 1 mile caused by accident sequence $m ; \operatorname{LERF}_{m}$ is the frequency of fatal early large release caused by accident sequence $m$; and TP(1) is the total population within 1 mile of the nuclear power plant. 


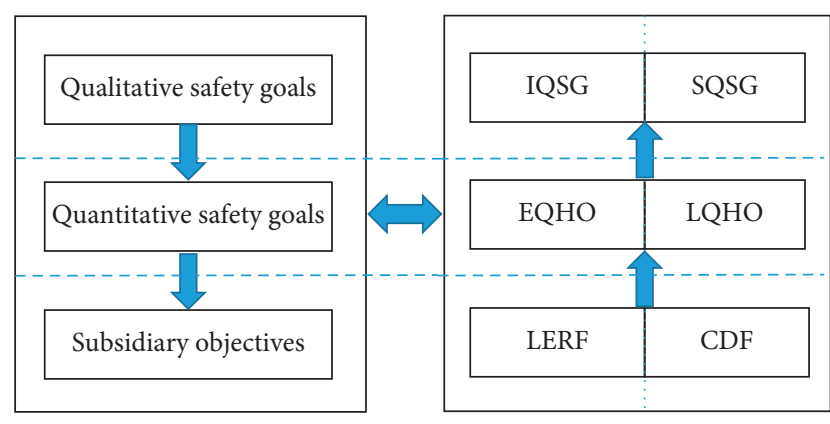

FIGURE 2: The relationship among nuclear safety goals in the US.

Then, in the population $\operatorname{TP}(1)$, the number of early prompt fatalities caused by accident sequence $m$ is given by

$$
\mathrm{EF}_{m}=\mathrm{CPEF}_{m} * \mathrm{TP}(1) .
$$

$\mathrm{CPEF}_{m}$ is the conditional probability of early prompt fatalities caused by accident sequence $m$, meaning the conditional probability of one person's early fatality caused by a radioactive release nuclear accident.

According to formulae (1) and (2), the individual early prompt fatality risk is

$$
\mathrm{IER}=\sum_{1}^{M} \mathrm{CPEF}_{m} * \mathrm{LERF}_{m}
$$

Suppose a worst accident sequence $m$, which has the greatest impact on early prompt fatalities risk. This accident sequence $m$ corresponds to a large break in the containment, and an unscrubbed release occurred before the surrounding population were effectively evacuated. According to the Surry PRA in NUREG-1150, the CPEF of the worst accident sequence is $3 \times 10^{-2}$.

Put $\mathrm{CPEF}=3 \times 10^{-2}$ and the safety goal value $\mathrm{LERF}=$ $1 \times 10^{-5} /(r \cdot y)$ into formula (3). Then, when the worst accident sequence $m$ occurs, the individual early prompt fatality risk is

$$
\begin{aligned}
\operatorname{IER}_{m} & =\left(3 \times 10^{-2}\right) \times\left(10^{-5}\right)=3 \times 10^{-7} /(r \cdot y)<\mathrm{IER}_{\mathrm{EQHO}} \\
& =5 \times 10^{-7} /(r \cdot y) .
\end{aligned}
$$

Therefore, using LERF $<10^{-5} /(r \cdot y)$ as a subsidiary goal of early quantitative health objectives (EQHO) for early prompt fatalities is acceptable.

2.2.3. $\mathrm{CDF}$ and $\mathrm{QHO}$ [20]. $\mathrm{CDF}<10^{-4} /(r \cdot y)$ is a subsidiary goal of latent quantitative health objectives (LQHO) for latent cancer fatalities. The rationality of substituting $\mathrm{CDF}$ for LQHO is demonstrated as follows.

According to the data survey for nuclear safety goals, the individual risk of cancer fatality from all other causes is $2 \times$ $10^{-3} / y$ in the US. According to the $0.1 \%$ in the latent quantitative health objective (LQHO), the individual latent risk ( $\mathrm{ILR}_{\mathrm{LQHO}}$ ) caused by nuclear power plant operations need to be less than $2 \times 10^{-6} /(r \cdot y)$. The area of a nuclear power plant means an extension of 10 mile from the boundary of the nuclear power plant. Individual latent risk (ILR) is

$$
\operatorname{ILR}=\sum_{1}^{N} \frac{\left(\mathrm{LF}_{n} * \mathrm{LLRF}_{n}\right)}{\mathrm{TP}(10)},
$$

where $\mathrm{LF}_{n}$ is the number of latent cancer fatalities within 10 miles caused by accident sequence $n ; \mathrm{LLRF}_{n}$ is the frequency of cancerogenic off-site individual doses caused by accident sequence $n$; and $\operatorname{TP}(10)$ is the total population within 10 miles of the nuclear power plant.

Then, in the population TP(10), the number of latent cancer fatalities caused by accident sequence $n$ is given by

$$
\mathrm{LF}_{n}=\mathrm{CPLF}_{n} * \mathrm{TP}(10),
$$

where $\mathrm{CPLF}_{n}$ is the conditional probability of latent cancer fatalities caused by accident sequence $n$.

According to formulae (5) and (6), the individual latent cancer risk is

$$
\operatorname{ILR}=\sum_{1}^{N} \mathrm{CPLF}_{n} * \mathrm{LLRF}_{n}
$$

Suppose a worst accident sequence $n$, which has the greatest impact on latent cancer fatalities risk. This accident sequence $n$ corresponds to a large opening in the containment, and an unscrubbed release occurred after the surrounding population were effectively evacuated. Suppose the worst accident occurs in an open containment; the conditional large latent release probability for accident sequence $n\left(\operatorname{CLLRP}_{n}\right)$ is 1.0 .

Then,

$$
\operatorname{LLRF}_{n}=\mathrm{CDF}_{n} * \mathrm{CLLRP}_{n}=\mathrm{CDF}_{n} * 1.0=\mathrm{CDF}_{n} .
$$

Putting formula (8) into formula (7), the risk of individual latent cancer fatality risk is

$$
\mathrm{ILR}_{n}=\mathrm{CPLF}_{n} * \mathrm{CDF}_{n} .
$$

According to the Surry PRA in NUREG-1150, the CPLF of the worst accident sequence is $4 \times 10^{-3}$.

Put CPLF $=4 \times 10^{-3}$ and the safety goal value $\mathrm{CDF}=$ $1 \times 10^{-4} /(r \cdot y)$ into formula (6). Then, when the worst accident sequence $n$ occurs, the individual latent cancer fatality risk is

$$
\begin{aligned}
\mathrm{ILR}_{n} & =\left(4 \times 10^{-3}\right) \times\left(10^{-4}\right)=4 \times 10^{-7} /(r \cdot y)<\mathrm{ILR}_{\mathrm{LQHO}} \\
& =2 \times 10^{-6} /(r \cdot y) .
\end{aligned}
$$

Therefore, using $\mathrm{CDF}<10^{-4} /(r \cdot y)$ as a subsidiary goal of latent quantitative health objectives (LQHO) for latent cancer fatalities is acceptable.

\section{Investigation into Chinese Societal Risk}

According to the process of determining probabilistic safety goals of USNRC, probabilistic safety goals are based on societal risks. Chinese current probabilistic safety goals refer 
to NRC and IAEA, and they are not based on Chinese societal risks. Therefore, we need to investigate the Chinese societal risks firstly and then formulate and verify probabilistic safety goals based on Chinese societal risks.

The data about the societal risk (i.e., mortality rate) can be obtained from the Chinese government and international organizations. Chinese statistics include the National Economic and Societal Development Statistical Bulletin and China's Health Statistical Yearbook [21, 22]. International organizations' statistics include World Health Organization's data [23] and World Bank's data [24].

According to the contents of probabilistic safety goals, we focus on early prompt fatalities and latent cancer fatalities caused by nuclear power plant operation which can be represented by accident mortality and cancer mortality in society, respectively.

In this section, the general overview of Chinese society was investigated firstly, including the analysis about main causes of fatalities in Chinese society, and then make a comparison between the death rate of China and several other countries.

3.1. Main Causes of Fatalities in China. The total population of China, the number of deaths, the number of urban and rural residents, and the GDP from 2012 to 2017 are shown in Table 1.

The mortality rates of different causes were counted, respectively, when counting the main causes of fatalities of Chinese population. Then, the causes of death were sorted according to the value of mortality. The source data are derived from the Chinese government and international organizations, and the statistical results were compared to ensure the authenticity of the data. Statistics from the Chinese government (2012-2017) are shown in Table 2. Statistics from international organizations $(2000,2010,2015$, and 2016) are shown in Table 3.

The causes of fatalities of Chinese population were counted based on the source data from Chinese government and international organizations as shown above. According to the comparison of the above data, the difference between the data obtained through the two channels is small, which proves that the statistics are true and reliable. The main causes of fatalities of Chinese population include malignant neoplasms, cerebrovascular diseases, heart diseases, respiratory diseases, and external causes of damage and poisoning.

3.2. Main Causes of Fatalities in Other Countries. It is necessary to investigate other countries' societal risks and compare the results with Chinese societal risks. On the one hand, the authenticity and reliability of the data can be proved through comparative analysis. On the other hand, investigating more countries' societal risks can help us to provide further suggestions for nuclear safety goals based on societal risks. China, the United States, Japan, the United Kingdom, France, India, Egypt, and Sudan were selected as the research object countries according to the development status and the level of nuclear power in each country. The causes of death and mortality in these countries in 2016 were counted, and the results are shown in Table 4.

According to the statistical data from international organizations, the causes of death and mortality of China, the United States, Japan, the United Kingdom, France, India, Egypt, and Sudan in 2016 were counted. According to the comparisons of the causes of death and mortality of China and the US, the societal fatalities' risks in China and in the US are similar. For example, the mortality rates caused by cardiovascular diseases, malignant neoplasms, respiratory diseases, and injuries are $317.10,167.88,66.47$, and 51.15 in China and 259.87, 194.83, 76.65, and 56.98 in the US. For probabilistic safety goals, we focus on the mortality rate of malignant neoplasms and external causes, which are similar between China and the US as well.

Furthermore, the nuclear safety goals of the US were formulated and revised from 1979 to 1986. According to data from international organizations, the mortality rate of malignant neoplasms and external causes in the United States from 1978 to 1985 were counted, and the results are shown in Table 5.

According to the statistical data in the table, the mortality rate of malignant neoplasms and external causes in the United States has not changed much from 1978 to 1985, and they are similar to the current risks of malignant neoplasms and external causes in China.

3.3. Probabilistic Safety Goals of Multimodule HTGR. High-temperature gas-cooled reactors are extremely unlikely to cause serious core damage and large early release due to inherent safety and unique design concepts. CDF and LERF proposed for water-cooled reactor are not suitable for high-temperature gas-cooled reactor. Therefore, the probabilistic safety goal of HTR-PM has been reestablished by China National Nuclear Safety Administration (NASA); that is, "the cumulative frequency of all beyond design basis accident sequences that lead to off-site (including plant boundary) personal effective dose exceeding $50 \mathrm{mSv}$ shall be less than $10^{-6} /(r \cdot y)$," and this risk metric is defined as the "frequency of LARGE release category" in HTR-PM probabilistic safety analysis (PSA) model. In this section, we verified the rationality of Chinese existing probabilistic safety goals for water reactors and then studied the probabilistic safety goals for Chinese high-temperature gascooled reactors.

3.4. Chinese Existing Probabilistic Safety Goals. The mortality rate of malignant neoplasms and external causes are important basis when verifying the rationality of Chinese existing CDF and LERF based on the current societal risks in China. According to the above statistics on Chinese societal risks, the statistical results of the mortality rate of malignant neoplasms and external causes are as follows. Statistics based on data from the Chinese government are shown in Table 6, and statistics based on data from international organizations are shown in Table 7.

According to the data from the Chinese government and international organizations shown in Tables 6 and 7, the 
TABLE 1: General overview of Chinese Society.

\begin{tabular}{cccccc}
\hline Year & Total population ('0000) & Dead population ('0000) & Urban population ('0000) & Rural population ('0000) & GDP (100 million) \\
\hline 2012 & 135404 & 966 & 71182 & 64222 & 519322 \\
2013 & 136072 & 972 & 73111 & 62961 & 568845 \\
2014 & 136782 & 977 & 74916 & 61866 & 636463 \\
2015 & 137462 & 975 & 77116 & 60346 & 676708 \\
2016 & 138271 & 977 & 79298 & 58973 & 744127 \\
2017 & 139008 & 986 & 81347 & 57661 & 827122 \\
\hline
\end{tabular}

Source: National Economic and Societal Development Statistical Bulletin [22].

TABle 2: Demographic mortality statistics in China based on Chinese data.

\begin{tabular}{|c|c|c|c|c|c|c|}
\hline Mortality rate $(1 / 100,000)$ & 2012 & 2013 & 2014 & 2015 & 2016 & 2017 \\
\hline Malignant neoplasms & 158.3 & 152.6 & 157.4 & 159.8 & 158.3 & 159.1 \\
\hline Cerebrovascular diseases & 127.7 & 137.0 & 137.6 & 139.4 & 140.0 & 139.4 \\
\hline Heart diseases & 125.9 & 138.3 & 139.6 & 140.2 & 144.0 & 146.9 \\
\hline Respiratory diseases & 89.0 & 76.0 & 76.8 & 76.3 & 74.4 & 71.9 \\
\hline External causes of damage and poisoning & 46.2 & 47.4 & 45.7 & 44.6 & 44.7 & 43.2 \\
\hline Other diseases & 26.4 & 8.2 & 6.8 & 6.2 & 6.1 & 6.0 \\
\hline Digestive diseases & 16.0 & 15.5 & 14.5 & 14.2 & 14.2 & 14.5 \\
\hline Endocrine, nutritional, and metabolic diseases & 14.2 & 14.6 & 15.6 & 17.1 & 18.4 & 18.8 \\
\hline Infectious & 6.9 & 7.4 & 7.2 & 7.2 & 7.0 & 6.7 \\
\hline Neurological conditions & 6.6 & 6.8 & 6.8 & 6.7 & 7.5 & 7.7 \\
\hline Genitourinary diseases & 6.5 & 6.7 & 6.9 & 6.8 & 6.9 & 7.1 \\
\hline Mental disorders & 2.5 & 2.8 & 2.7 & 2.8 & 2.8 & 2.7 \\
\hline Acatalepsia & 2.3 & 2.5 & 2.5 & 2.3 & 2.2 & 2.1 \\
\hline Neonatal conditions & 2.3 & 2.2 & 2.3 & 1.9 & 2.0 & 1.7 \\
\hline Congenital anomalies and chromosomal abnormalities & 2.0 & 2.1 & 2.0 & 1.8 & 1.6 & 1.6 \\
\hline Musculoskeletal diseases & 1.4 & 1.7 & 1.7 & 1.7 & 2.0 & 2.1 \\
\hline Blood, hematopoietic organ, and immune disorders & 1.2 & 1.2 & 1.2 & 1.2 & 1.3 & 1.3 \\
\hline Complications of pregnancy, childbirth, and puerperium & 0.1 & 0.1 & 0.1 & 0.1 & 0.1 & 0.1 \\
\hline Parasitic diseases & 0.1 & 0.1 & 0.0 & 0.1 & 0.1 & 0.1 \\
\hline
\end{tabular}

Source: China's Health Statistical Yearbook [21]. Note. External causes of injury and poisoning include traffic accidents, poisoning, falls, fires, natural disasters, mechanical asphyxiation, suicide, homicide, and mechanical injuries.

individual latent cancer fatality risk (ILCFR) is about $1.6 \times 10^{-3} / y$, and the individual early prompt fatality risk (IEPFR) is about $5 \times 10^{-4} / y$.

According to the Chinese societal risks, the reasonability of existing probabilistic safety goals in China is shown in Figure 3. Based on the Chinese societal risks and quantitative safety goals ("two $0.1 \%$ rule"), the individual latent cancer fatality risk caused by nuclear power plant operation $\left(\mathrm{ILCFR}_{\mathrm{NPP}}\right)$ should be less than $1.6 \times 10^{-6} / y$, and the individual early prompt fatality risk caused by nuclear power plant accidents $\left(\right.$ IEPFR $_{\mathrm{NPP}}$ ) should be less than $5 \times 10^{-7} / y$. Based on the subsidiary safety goals and the assessment of nuclear power plant, the $\mathrm{ILCFR}_{\mathrm{NPP}}$ is less than $4 \times 10^{-8} / y$, and the IEPFR $\mathrm{NPP}_{\mathrm{N}}$ is less than $3 \times 10^{-8} / y$. As shown above, Chinese current probabilistic safety goals can meet the needs of Chinese societal risks control.

3.5. Probabilistic Safety Goals of Multimodule HTGR. The design characteristics and defense-in-depth measures of multimodule HTGR nuclear power plants are different from those of water reactor nuclear power plants. Due to the safety design concept, inherent safety, and passive safety measures, there is extremely low large release frequency and longer time before radioactive material is released into the environment. So, there is longer time for postaccident mitigation and emergency response, allowing more measures to actually eliminate core damage and large early release. Therefore, it uses the "frequency of LARGE release category" defined in HTGR PSA as the risk index rather than the CDF or LERF. According to the risk metric of HTR-PM, it should be less than $10^{-6} /(r \cdot y)$. However, it should be noted that this safety goal is dedicated to HTRPM project, and it is focused on single reactor rather than unit (two reactors and one turbine). Therefore, this paper tries to study whether this risk metric can be extended to be applied to the multimodule HTGR; that is, can we use the "frequency of LARGE release category less than $10^{-6} /($ unit $\cdot y)$ or $10^{-6} /($ site $\cdot y)$ as the risk metric of multimodule HTGR directly.

In the following, we will use the risk metric of HTR-PM to demonstrate the margin of probabilistic safety goal.

The "LARGE" release category of HTR-PM is similar to the LERF of water reactors, and it focuses on early prompt fatalities risks and EQHO. Individual early risk (IER) is 
TABle 3: Demographic mortality statistics in China based on the WHO data.

\begin{tabular}{lcccc}
\hline Mortality rate $(1 / 100,000)$ & 2000 & 2010 & 2015 & 2016 \\
\hline Cardiovascular diseases & 212.8 & 269.6 & 309.5 & 317.1 \\
Malignant neoplasms & 144.4 & 159.9 & 166.3 & 167.9 \\
Respiratory diseases & 97.5 & 71.2 & 65.9 & 66.5 \\
External causes of damage and & 60.7 & 54.0 & 50.9 & 51.2 \\
poisoning & 20.6 & 32.3 & 42.0 & 44.9 \\
Neurological condition & 18.3 & 17.4 & 19.2 & 19.7 \\
Digestive diseases & 9.8 & 12.3 & 14.9 & 15.2 \\
Genitourinary diseases & 19.2 & 12.6 & 12.4 & 12.6 \\
Respiratory infectious & 7.7 & 9.7 & 11.6 & 11.9 \\
Diabetes mellitus & 18.6 & 12.0 & 9.6 & 9.2 \\
Infectious and parasitic diseases & 18.0 & 8.0 & 5.4 & 4.9 \\
Neonatal conditions & 2.1 & 2.6 & 3.1 & 3.2 \\
Mental and substance use disorders & 6.7 & 4.6 & 3.3 & 3.1 \\
Congenital anomalies & 1.5 & 2.4 & 2.9 & 2.9 \\
Other neoplasms & 1.5 & 1.4 & 1.7 & 1.7 \\
Endocrine, blood, and immune & 1.1 & 1.3 & 1.5 & 1.5 \\
disorders & 1.4 & 0.9 & 1.1 & 1.1 \\
Musculoskeletal diseases & 0.3 & 0.4 & 0.5 & 0.5 \\
Nutritional deficiencies & 0.1 & 0.1 & 0.1 & 0.1 \\
Skin diseases & Sudden infant death syndrome &
\end{tabular}

Source: World Health Organization statistics [23]. Note. External causes of injury and poisoning include road injury, poisonings, falls, fire, heat and hot substances, drowning, exposure to mechanical forces, natural disasters, other unintentional injuries, self-harm, interpersonal violence, collective violence, and legal intervention.

$$
\operatorname{IER}=\sum_{1}^{H} \frac{\left(\mathrm{EF}_{h} * \mathrm{LARGE}_{h}\right)}{\mathrm{TP}(1)}
$$

where $\mathrm{EF}_{h}$ is the number of early prompt fatalities within 1 mile caused by accident sequence $h$. LARGE ${ }_{h}$ is the frequency of fatal LARGE categories caused by accident sequence $h$ TP (1) is the total population within 1 mile of the nuclear power plant.

Then, in the population $\mathrm{TP}(1)$, the number of early prompt fatalities caused by accident sequence $h$ is

$$
\mathrm{EF}_{h}=\mathrm{CPEF}_{h} * \mathrm{TP}(1)
$$

where $\mathrm{CPEF}_{h}$ is the conditional probability of early prompt fatalities caused by accident sequence $h$, meaning the conditional probability of one person's early fatality caused by a radioactive release nuclear accident.

According to formulae (9) and (10), the individual early prompt fatality risk is

$$
\mathrm{IER}=\sum_{1}^{H} \mathrm{CPEF}_{h} * \mathrm{LARGE}_{h}
$$

According to the data survey for Chinese societal risks, the individual risk of prompt fatality caused by all other accidents is $5 \times 10^{-4} / y$ in China. According to the $0.1 \%$ in the early quantitative health objective (EQHO), the individual early risk ( $\mathrm{IER}_{\mathrm{EQHO}}$ ) caused by nuclear power plant accidents needs to be less than $5 \times 10^{-7} /(r \cdot y)$. Suppose a worst accident sequence $h$, which has the greatest impact on early prompt fatalities risk. An unscrubbed release occurred before the surrounding population were effectively evacuated.

Suppose

$$
\mathrm{IER}_{h}=\mathrm{CPEF}_{h} * \mathrm{LARGE}_{\mathrm{h}}=\mathrm{IER}_{\mathrm{EQHO}}=\frac{5 \times 10^{-7}}{(r \cdot y)} .
$$

According to the probabilistic safety goals for multiHTGR, LARGE $=1 \times 10^{-6} /(r \cdot y)$.

Thus, $\mathrm{CPEF}_{h}=0.5$.

That is, the conditional probability of early prompt fatalities caused by the worst accident sequence $h$ is 0.5 ; it just meets the EQHO for individual early prompt fatalities risks.

In the International Commission on Radiological Protection (ICPR) Publication 60, according to the dose threshold of the deterministic effects, the 60-day median lethal dose $\left(\mathrm{LD}_{50}[60]\right)$ is $3 \sim 5 \mathrm{~Gy} /$ time. The probability of stochastic effects increases with increasing dose. Stochastic effects include cancer and hereditary diseases. For cancer, the probability coefficients of fatal cancer are $5 \times 10^{-2} / \mathrm{Sv}$ for the public and $4 \times 10^{-2} / \mathrm{Sv}$ for occupational workers engaged in radiation. For hereditary diseases, the probability coefficients of hereditary diseases are $1 \times 10^{-2} / \mathrm{Sv}$ for the public and $0.6 \times 10^{-2} / \mathrm{Sv}$ for workers. ICPR 103 followed the conclusion of the ICRP 60; the combined detriment due to fatal cancer and hereditary diseases remains unchanged at around $5 \times 10^{-2} / \mathrm{Sv}$. For HTR-PM, there is extremely low large release frequency, and the personal effective dose control threshold is $50 \mathrm{mSv}$. According to the results of above analysis, when $\mathrm{LARGE}_{h}=1 \times 10^{-6} /(r \cdot y)$ and $\mathrm{CPEF}_{h}=0.5$, the risk metric of HTR-PM can meet the requirements of Chinese societal risks. In fact, the personal effective dose control threshold is $50 \mathrm{mSv}$, and actual $\mathrm{CPEF}_{h}$ is extremely low as well, so the risk metric of HTR-PM has large margin compared with Chinese societal risk. Therefore, it give us the confidence to expand the risk metric of HTRPM (i.e., $1 \times 10^{-6} /$ reactor $\cdot y$ ) to multimodule HTGR (i.e., $1 \times 10^{-6} /($ unit $\cdot y)$ or $1 \times 10^{-6} /($ site $\cdot \leq y)$ ), and then the risk metric of multimodule HTGR can meet the requirements of Chinese societal risks.

\section{Discussions}

Existing nuclear safety goals is mainly for a single reactor. But in fact, most of the plant sites are multireactor sites. Multireactor site means a nuclear power plant site with two or more reactors on one site. From the Fukushima nuclear accident, we realized the possibility and severity of nuclear accidents occurring at multiple reactors at the same time. Nuclear safety goals are set to protect the lives, health, and environment of populations. For the populations, not only the impact of a single reactor on the human body must be considered, but also the impact of the entire plant site on the human body.

For example, expand the risk metric of HTR-PM from a single reactor to a plant site and explore the adaptability of probabilistic safety goals. The current probabilistic safety goals of HTR-PM are that the cumulative frequency of all accident sequences that cause the personal effective dose 
TABLE 4: Demographic mortality statistics in different countries.

\begin{tabular}{|c|c|c|c|c|c|c|c|c|}
\hline Mortality rate $(1 / 100,000)$ & China & The US & Japan & The UK & France & India & Egypt & Sudan \\
\hline All causes & 734.9 & 869.8 & 1026.0 & 912.4 & 861.6 & 722.6 & 635.9 & 712.3 \\
\hline Cardiovascular diseases & 317.1 & 259.9 & 280.8 & 228.7 & 221.6 & 195.6 & 257.0 & 202.9 \\
\hline Malignant neoplasms & 167.9 & 194.8 & 312.9 & 255.7 & 267.9 & 61.6 & 81.2 & 44.6 \\
\hline Respiratory diseases & 66.5 & 76.7 & 90.1 & 76.0 & 48.0 & 76.8 & 27.1 & 22.1 \\
\hline Injuries & 51.2 & 57.0 & 49.7 & 31.8 & 54.8 & 81.8 & 36.7 & 89.6 \\
\hline Neurological conditions & 44.9 & 102.1 & 41.8 & 149.9 & 99.5 & 15.8 & 22.1 & 16.3 \\
\hline Digestive diseases & 19.7 & 36.7 & 45.3 & 43.5 & 38.4 & 38.5 & 83.4 & 20.9 \\
\hline Genitourinary diseases & 15.2 & 26.7 & 34.7 & 16.1 & 16.4 & 23.0 & 19.7 & 19.8 \\
\hline Respiratory infectious diseases & 12.6 & 20.6 & 110.7 & 57.1 & 27.7 & 46.6 & 23.1 & 48.2 \\
\hline Diabetes mellitus & 11.9 & 26.2 & 11.3 & 10.0 & 19.1 & 23.3 & 18.7 & 14.6 \\
\hline Infectious and parasitic diseases & 9.2 & 17.5 & 17.0 & 10.1 & 15.4 & 90.6 & 12.4 & 101.1 \\
\hline Neonatal conditions & 4.6 & 3.6 & 0.5 & 2.5 & 2.4 & 41.5 & 26.8 & 89.4 \\
\hline Mental and substance use disorders & 3.2 & 14.9 & 1.8 & 5.7 & 9.2 & 2.4 & 0.6 & 1.6 \\
\hline Congenital anomalies & 3.1 & 4.0 & 2.2 & 3.5 & 3.0 & 7.9 & 15.1 & 18.0 \\
\hline Other neoplasms & 2.9 & 5.1 & 9.9 & 6.0 & 11.8 & 1.1 & 3.8 & 3.2 \\
\hline Endocrine, blood, and immune disorders & 1.7 & 14.1 & 8.2 & 4.8 & 10.8 & 1.6 & 5.2 & 5.4 \\
\hline Musculoskeletal diseases & 1.5 & 4.5 & 5.2 & 7.0 & 6.7 & 3.7 & 0.2 & 0.7 \\
\hline Nutritional deficiencies & 1.1 & 3.0 & 2.5 & 0.6 & 6.5 & 6.3 & 1.4 & 3.4 \\
\hline Skin diseases & 0.5 & 1.6 & 1.5 & 3.1 & 2.1 & 1.0 & 0.1 & 0.8 \\
\hline Maternal conditions & 0.3 & 0.2 & 0.0 & 0.1 & 0.1 & 3.1 & 0.9 & 9.0 \\
\hline Sudden infant death syndrome & 0.1 & 0.5 & 0.1 & 0.2 & 0.2 & 0.4 & 0.6 & 0.9 \\
\hline Sense organ diseases & . & 0.0 & 0.0 & 0.1 & 0.1 & . & . & . \\
\hline Oral conditions & . & 0.1 & 0.1 & 0.1 & 0.2 & 0.0 & . & . \\
\hline
\end{tabular}

Source: World Health Organization statistics [23].

TABLE 5: The mortality rate of malignant neoplasms and external causes in the US.

\begin{tabular}{lcccccccc}
\hline Mortality rate $(1 / 100,000)$ & 1978 & 1979 & 1980 & 1981 & 1982 & 1983 & 1984 & 1985 \\
\hline Malignant neoplasms & 161.7 & 175.4 & 179.5 & 180.2 & 183.6 & 185.9 & 188.7 & 190.5 \\
External causes & 70.7 & 70.6 & 70.7 & 67.8 & 63.8 & 61.6 & 61.5 & 61.2 \\
\hline
\end{tabular}

Source: World Health Organization statistics [23].

TABLE 6: The mortality rate of malignant neoplasms and external causes in China (1).

\begin{tabular}{lccccccc}
\hline Mortality rate $(1 / 100,000)$ & 2012 & 2013 & 2014 & 2015 & 2016 & 2017 & Average \\
\hline Malignant neoplasms & 158.3 & 152.6 & 157.4 & 159.8 & 158.3 & 159.1 & 157.6 \\
External causes & 46.2 & 47.4 & 45.7 & 44.6 & 44.7 & 43.2 & 45.3 \\
\hline
\end{tabular}

TABLE 7: The mortality rate of malignant neoplasms and external causes in China (2).

\begin{tabular}{lccccc}
\hline Mortality rate $(1 / 100,000)$ & 2016 & 2015 & 2010 & 2000 & Average \\
\hline Malignant neoplasms & 167.9 & 166.3 & 159.9 & 144.4 & 159.6 \\
External causes & 51.2 & 50.9 & 54.0 & 60.7 & 54.2 \\
\hline
\end{tabular}

outside the plant (including the site boundary) to exceed $50 \mathrm{mSv}$ is less than $10^{-6} /(r \cdot y)$. Expanding from a single reactor to a plant site means LARGE $=10^{-6} /$ (reactor $\cdot$ year) changed to LARGE $=10^{-6} /($ site $\cdot$ year $)$ (site $\cdot$ year, $\left.s \cdot y\right)$.

Through the derivation in Section 4, LARGE $=10^{-6} /(s \cdot y)$; then, $\mathrm{CPEF}_{h}=0.5$. That is, the conditional probability of early prompt fatalities caused by the worst accident sequence $h$ in the entire plant site is 0.5 ; it just meets the EQHO for individual early prompt fatalities' risks.

Suppose there are two reactors in a plant site, and suppose that the two reactors suffer the worst accident sequence at the same time. In order to ensure the probabilistic safety goals of the multimodule HTGR site and ensure a sufficient safety margin, it is necessary to ensure the cumulative frequency of beyond design basis accidents with a 


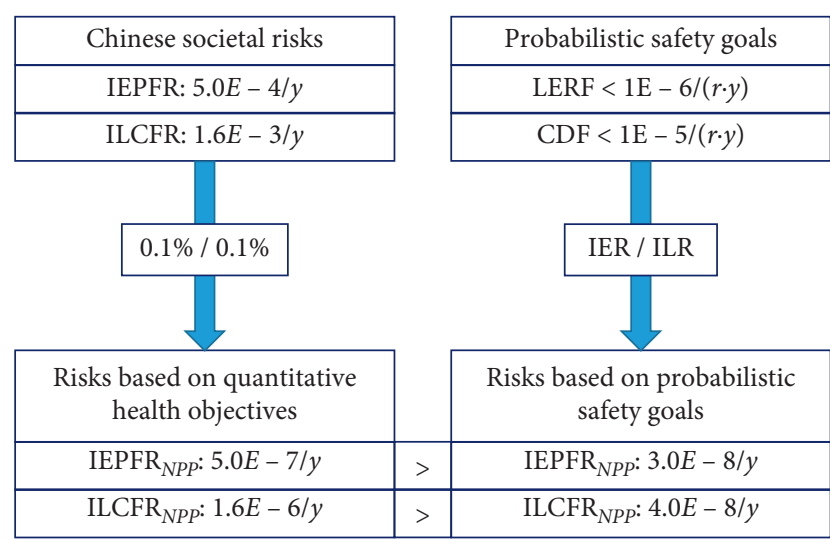

FIgURE 3: The rationality of existing probabilistic safety goals in China.

personal effective dose exceeding $50 / 2=25 \mathrm{mSv}$ for each reactor is less than $10^{-6} / 2=5 \times 10^{-7} /(r \cdot y)$.

In fact, the individual effective dose and cumulative frequency caused by the entire plant site are not necessarily the simple addition of the individual effective dose and cumulative frequency caused by each single reactor. However, in order to ensure the probabilistic safety goals, the value of the probabilistic safety goals of each single reactor is smaller than the entire plant site. We need to consider the following points:

(a) The safety and reliability of a single reactor is constant. The number of reactors on the site needs to be controlled and cannot be increased indefinitely.

(b) The design of the reactors can still be based on the single reactor for the convenience of design. But for the entire plant site, we can consider different types of reactors with different risk levels at the same site.

\section{Conclusions}

According to the statistics on societal risks in China, the individual latent cancer fatality risk (ILCFR) is $1.6 \times 10^{-3} / y$, and the individual early prompt fatality risk (IEPFR) is $5 \times 10^{-4} / y$. The mortality rates are similar in China and the United States, and the changes in recent years are small. The Chinese current probabilistic safety goals can meet the requirement of little contribution to social risks.

The probabilistic safety goals of HTR-PM recommended by China's National Nuclear Safety Administration (NNSA) are as follows: the cumulative frequency of all beyond-design-basis accident sequences that lead to off-site (including plant boundary) personal effective dose exceeding $50 \mathrm{mSv}$ shall be less than $10^{-6} /(r \cdot y)$. According to the inference, the probabilistic safety goals are rational. And the risk metric of HTR-PM has large margin according to the societal risk of China; maybe, it can be extended to be applied to the multimodule HTGR as "frequency of LARGE release category less than $10^{-6} /\left(\right.$ unit $\cdot y$ ) or $10^{-6} /($ site $\cdot y) . "$

In the end, we think it is better that the probabilistic safety goals based on entire plant site rather than a single reactor. We need to control the number of reactors on one site, and we can consider different types of reactors with different risk levels at the same site. And the above analysis process is applicable to other types of reactors.

\section{Data Availability}

The data used in this paper are obtained from China $\mathrm{Na}$ tional Bureau of Statistics (http://www.stats.gov.cn/) and World Health Organization (https://www.who.int/data/ collections).

\section{Conflicts of Interest}

The authors declare that they have no conflicts of interest regarding the publication of this paper.

\section{Acknowledgments}

This study was supported by the National Science and Technology Major Project (2018ZX06902015) and the National Natural Science Foundation of China (Project no. 71601139).

\section{References}

[1] C. Meyer, "China and nuclear energy: solving an energy crisis-part 4," Energize, vol. 7, no. 42, pp. 18-19, 2011.

[2] J. Wood, "Nuclear safety and three major accidents," Nuclear Power. IET Digital Library, vol. 18, no. 6, 2007.

[3] OECD/NEA, Probabilistic Risk Criteria and Safety Goals, $N E A / C S N I / R$, Organization for Economic Cooperation and Development/Nuclear Energy Agency (OECD/NEA), Paris, France, 2009.

[4] Z. Zhang, Z. Wu, and Y. Sun, "Design aspects of the Chinese modular high-temperature gas-cooled reactor HTR-PM," Nuclear Engineering \& Design, vol. 236, no. 5-6, pp. 485-490, 2006.

[5] IAEA, "Policy for setting and assessing regulatory safety goals," 1995.

[6] EPRI, "Advanced light water reactor utility requirements document," ALWR Policy and Summary of Top-Tier Requirements, vol. 1, 1990.

[7] K. R. KEMA, "European utility requirements for LWR nuclear power plants," Main Policies and Top Tier Requirements, Revision B, vol. 1, 1995.

[8] GPR-RSK, "IPSN-GRS proposals for the development of technical guideline for future pWRs," 1997.

[9] IAEA, Safety Series 75-INSAG-3, Basic Safety Principles for Nuclear Power Plants, IAEA, 1988, https://www.google.com/ search?rlz=1C1GCEJ_enIN954IN954\&q=Vienna\&stick=H4sI AAAAAAAAAOPgE-LQz9U3MC43slACs9IyCiyltLKTrfTzi9 IT8zKrEksy8_NQOFYZqYkphaWJRSWpRcWLWNnCMlPz8 hJ3sDICANR77yBOAAAA\&sa=X\&ved=2ahUKEwipg5u38-z wAhULIbcAHc0pBCcQmxMoATA4egQINRAD.

[10] IAEA, Safety Series 75-INSAG-12, Basic Safety Principles for Nuclear Power Plants, IAEA, 1999, https://www.google.com/ search?rlz=1C1GCEJ_enIN954IN954\&q=Vienna\&stick=H4s IAAAAAAAAAOPgE-LQz9U3MC43slACs9IyCiyltLKTrfTzi 9IT8zKrEksy8_NQOFYZqYkphaWJRSWpRcWLWNnCMlP z8hJ3sDICANR77yBOAAAA\&sa=X\&ved=2ahUKEwipg5u3 8-zwAhULIbcAHc0pBCcQmxMoATA4egQINRAD. 
[11] IAEA, Safety Standards Series No.NS-R-1, Safety of Nuclear Power Plants: Design, IAEA, 2000, https://www.google.com/ search?rlz=1C1GCEJ_enIN954IN954\&q=Vienna\&stick=H4s IAAAAAAAAAOPgE-LQz9U3MC43slACs9IyCiy1tLKTrfTz i9IT8zKrEksy8_NQOFYZqYkphaWJRSWpRcWLWNnCMl Pz8hJ3sDICANR77yBOAAAA\&sa=X\&ved=2ahUKEwipg5u 38-zwAhULIbcAHc0pBCcQmxMoATA4egQINRAD.

[12] IAEA, Safety Standards Series No.NS-G-1.2, Safety Assessment and Verification for Nuclear Power Plants, IAEA, 2001, https:// www.google.com/search?rlz=1C1GCEJ_enIN954IN954\&q=Vi enna\&stick=H4sIAAAAAAAAAOPgE-LQz9U3MC43slACs9I yCiyltLKTrfTzi9IT8zKrEksy8_NQOFYZqYkphaWJRSWpRc WLWNnCMIPz8hJ3sDICANR77yBOAAAA\&sa=X\&ved=2ah UKEwipg5u38-zwAhULIbcAHc0pBCcQmxMoATA4egQINR $\mathrm{AD}$.

[13] USNRC, 51 Federal Register 7023, Safety Goals for the Operation of Nuclear Power Plants; Policy Statement, USNRC, Rockville, MD, USA, 1982.

[14] USNRC, 51 Federal Register 10772, Safety Goals for the Operation of Nuclear Power Plants; Policy Statement, USNRC, Rockville, MD, USA, 1983.

[15] USNRC, 51 Federal Register 30028, Safety Goals for the Operation of Nuclear Power Plants; Policy Statement; Republication. Federal Register, USNRC, Rockville, MD, USA, 1986.

[16] China National Nuclear Safety Administration, Provisions on Design Safety of Nuclear Power Plant, HAF102, National Nuclear Safety Administration, 1991, Beijing, China, 2016.

[17] China National Nuclear Safety Administration, Safety Evaluation and Validation of Nuclear Power Plant, National Nuclear Safety Administration, Beijing, China, 2006.

[18] China National Nuclear Safety Administration, Twelfth FiveYear Plan and Vision 2020 for Nuclear Safety and Radioactive Pollution Prevention, Beijing, China Environmental News, Beijing, China, 2012.

[19] China National Nuclear Safety Administration, Thirteenth Five-Year Plan and Vision 2025 for Nuclear Safety and Radioactive Pollution Prevention, Beijing, China Environmental News, Beijing, China, 2017.

[20] USNRC. NUREG-1860, Feasibility Study for a Risk-Informed and Performance-Based Regulatory Structure for Future Plant Licensing, Washing DC: United States Nuclear Regulatory Commission, Washington, DC, USA, 2007.

[21] China National Health Commission, China Health Statistical Yearbook, China Union Medical College Press, Beijing, China, 2017.

[22] China National Bureau of Statistics, National Economic and Societal Development Statistical Bulletin, National Bureau of Statistics, Beijing, China, 2017.

[23] World Health Organization, Global Health Estimates Summary Tables, WHO, Geneva, Switzerland, 2021, http://www. who.int/healthinfo/global_burden_disease/en/.

[24] The World Bank, Free and Open Access to Global Development Data, The World Bank, Washington, DC, USA, 2021, https:// data.worldbank.org/. 